\title{
COMPARISON OF MATERNAL AND PERINATAL OUTCOME IN ELECTIVE AND EMERGENCY CESAREAN SECTION IN A TERTIARY CARE CENTRE
}

\author{
Subedi $A,{ }^{1 *}$ Shrestha $J^{2}$ Adhikari $K M,{ }^{3}$ Shrestha $A,{ }^{1}$ Gurung $S^{1}$
}

\section{Affiliation}

1. Lecturer, Department of Obstetrics \& Gynecology, Manipal College of Medical Sciences, Pokhara, Nepal

2. Associate professor, Department of Obstetrics \& Gynecology, Manipal College of Medical Sciences, Pokhara, Nepal

3. Lecturer, Department of Anesthesiology, Manipal College of Medical Sciences, Pokhara, Nepal

\section{ARTICLE INFO}

\section{Article History}

\begin{tabular}{|c|c|}
\hline ceived & 5 February, 20 \\
\hline Accepted & 22 April, 2019 \\
\hline blicho & \\
\hline
\end{tabular}

(C) Authors retain copyright and grant the journal right of first publication with the work simultaneously licensed under Creative Commons Attribution License CC - BY 4.0 that allows others to share the work with an acknowledgment of the work's authorship and initial publication in this journal.

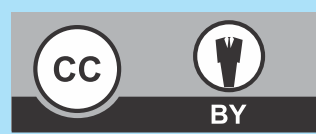

\section{ORA 101}

DOI: $\underline{\text { http://dx.doi.org/10.3126/bjhs.v4i1.23933 }}$

\section{* Corresponding Author}

Dr. Anjali Subedi

Lecturer

Department of Obstetrics \& Gynecology

Manipal College of Medical Sciences, Pokhara, Nepal

Email: anzee739@gmail.com

ORCID ID: https://orcid.org/0000-0002-9809-6180

\section{Citation}

Subedi A, Shrestha J, Adhikari KM, Shrestha A, Gurung S.Comparison of Maternal and Perinatal Outcome in Elective and Emergency Cesarean Section in A Tertiary Care Centre. BJHS 2019;4(1)8: 616 - 620.

\begin{abstract}
Introduction

Cesarean delivery is the birth of a fetus via laparotomy and then hysterotomy. There are increased maternal and fetal morbidities and mortalities associated with such delivery, more in emergency cesarean section. Various studies have shown increasing trend of this mode of delivery worldwide leading to an increase in its associated risks and cost to the patients.
\end{abstract}

\section{Objective}

The objective of the study was to compare the maternal and perinatal outcome in elective and emergency cesarean section.

\section{Methodology}

It was a prospective comparative study conducted in the department of obstetrics and gynecology, Manipal Teaching Hospital from March, 2018 to September, 2018. All the patients undergoing cesarean section either elective or emergency were enrolled in the study after their consent. After collecting data from patients, maternal and perinatal outcomes were analyzed by using SPSS software.

\section{Results}

There were total 1254 deliveries in the study duration, out of which 461(36.76\%) were cesarean section (cs). The incidence of emergency cs was $86.5 \%$ and elective cs was $13.5 \%$. Majority of women (75.7\%) undergoing cs had no any antenatal visit. Around $81 \%$ of cases undergoing emergency cs were unbooked whereas only $48.4 \%$ of unbooked cases underwent elective cs (P-value 0.000). The most common indication for cs in both elective and emergency category was previous cs. There was no maternal complication in elective cs group but there were 8 cases $(2 \%)$ in emergency cs (P value-0.293). In emergency cs group, 7 babies had poor Apgar score whereas all babies had good Apgar score in elective group (P-value-0.057). There was increased rate of $\mathrm{NICU}$ admission in emergency group than in elective group ( $3 \%$ vs $0 \%$, P value- 0.166 ).

\section{Conclusion}

The study showed that the incidence of cesarean section was high in our centre. The maternal and fetal risks were higher in emergency cs than in elective cs, but these were not statistically significant.

\section{KEY WORDS}

Cesarean section, pregnancy, perinatal, tertiary care centre 


\section{INTRODUCTION}

Cesarean delivery is the birth of a fetus via laparotomy and then hysterotomy. ${ }^{1}$ Depending upon the time of operation, it is divided into elective and emergency cesarean section (cs). Cesarean section is associated with increased risk of maternal and perinatal morbidity and mortality in comparison to vaginal delivery. ${ }^{2}$ It is seen that morbidity and mortality are associated more with emergency cesarean sections than with elective ones. ${ }^{3,4}$

According to WHO, the cs rate should be in between $10-15 \%$ as rate above this has not shown any improvement in the maternal and perinatal outcomes.

Recently, there has been an alarming increase in the rate of cesarean section globally, predisposing women to increased risk and cost of the surgery. According to the latest data from 150 countries, currently $18.6 \%$ of all births occur by cesarean route, ranging from $6 \%$ to $27.2 \%$ in the least and most developed regions, respectively. Based on the data from 121 countries, the trend analysis showed that between 1990 and 2014, the global average cs rate increased $12.4 \%$ (from $6.7 \%$ to $19.1 \%$ ) with an average annual rate of increase of $4.4 \%$.

In our centre, the cesarean rate is around $40 \%$ from the annual records and till now no studies have been done to evaluate the maternal and perinatal outcome. So this study aims to compare maternal and perinatal morbidities in elective and emergency cesarean sections in a tertiary care centre.

\section{METHODOLOGY}

It was a hospital based comparative study which was conducted in the Department of Obstetrics and Gynecology, Manipal Teaching Hospital, Pokhara. The study was conducted from March, 2018 to September, 2018. After taking approval from Institutional Review Committee, all the patients undergoing cesarean section either elective or emergency cesarean sections were enrolled in the study after their consent.

After the cases were enrolled, detailed history regarding age, parity, booking status, previous obstetric outcome, any significant past, family and personal history were taken and noted in a predesigned proforma. Booking status of the patient was defined as women having at least 3 antenatal visits in our centre. Indications for cesarean section, intra operative complications were noted. The cases were followed for 7 days postpartum and any puerperal complications like puerperal pyrexia, secondary postpartum hemorrhage (PPH), wound infection or maternal mortality were noted.

In cases of maternal mortality, further details were taken from the records of the deceased patients.

For evaluation of perinatal outcome, Apgar score at 5 minute, need of NICU admission, still birth and early neonatal death were recorded.

The data were entered and analyzed using SPSS software and results were expressed in terms of percentage, categorical data were compared using Chi square and means were compared using unpaired $t$ test and $P$ value $<.05$ was taken significant.

\section{RESULTS}

There were total 1254 deliveries in the study period. Total number of cesarean section was 461, the incidence being $36.76 \%$ of total deliveries. Among 461 cesarean section, 399 $(86.5 \%)$ were emergency and $62(13.5 \%)$ were elective cs.

The mean age in elective cs was $27.98 \pm 4.083$ and emergency cs was $25.71 \pm 4.809$ and this difference in mean age was statistically significant (P value-0.000) (Table 1).

Table 1: Age Distribution
\begin{tabular}{|l|c|c|c|}
\hline & \multicolumn{2}{|c|}{ Type of cesarean section } & P value \\
\cline { 2 - 3 } & Elective cs & Emergency cs & \\
\hline Mean age & $27.98 \pm 4.809$ & $25.71 \pm 4.809$ & 0.000 \\
\hline
\end{tabular}

In elective cs group, $56.5 \%$ were booked and $43.5 \%$ were unbooked cases. In emergency cs, majority of cases (80.7\%) were unbooked and only $19.3 \%$ cases were booked. So unbooked cases underwent more emergency cs than elective cs and this was statistically significant (Table 2).

Table 2: Booking status of patients
\begin{tabular}{|l|c|c|c|}
\hline \multirow{2}{*}{ Booking status } & \multicolumn{2}{|c|}{ Type of cesarean section } & \multirow{2}{*}{ P_value } \\
\cline { 2 - 3 } & Elective cs (n,\%) & Emergency cs (n,\%) & \multirow{2}{*}{0.000} \\
\hline Booked & $35(56.5)$ & $77(19.3)$ & $321(80.7)$ \\
\hline Unbooked & $27(43.5)$ & \\
\hline
\end{tabular}

In the study, the most common indication for cesarean section in both elective and emergency cesarean groups was previous cs, accounting $43.54 \%$ in elective cases and $19.29 \%$ in emergency cases. The other common indications for cs in elective and emergency groups were cephalopelvic disproportion (CPD) (22.58\% vs $11.58 \%$ ) and breech (19.39\% vs $5.26 \%$ ). In emergency cases, the other common indications were oligohydraminos (17.54\%), meconium stained liquor (17.04\%), fetal heart rate abnormality (11.02\%), non progress of labor $(7.76 \%)$ and hypertensive disorders in pregnancy $(5.76 \%)$.

Table 3: Indication of cesarean section
\begin{tabular}{|l|c|c|}
\hline \multicolumn{1}{|c|}{ Indication of cs } & $\begin{array}{c}\text { Elective cs (62) } \\
\text { N(\%) }\end{array}$ & $\begin{array}{c}\text { Emergency cs } \\
(399) \text { N(\%) }\end{array}$ \\
\hline Previous cs & $27(43.54)$ & $77(19.29)$ \\
\hline Cephalopelvic proportion(CPD) & $14(22.58)$ & $46(11.58)$ \\
\hline Breech & $12(19.39)$ & $21(5.26)$ \\
\hline Oligohydraminos & $1(1.61)$ & $70(17.54)$ \\
\hline Meconium stained liquor & 0 & $68(17.04)$ \\
\hline Fetal heart rate abnormality & 0 & $44(11.02)$ \\
\hline Non progress of labor & 0 & $31(7.76)$ \\
\hline Hypertensive disorder & $1(1.61)$ & $23(5.76)$ \\
\hline Antepartum hemorrhage & 0 & $5(1.25)$ \\
\hline Bad obstetric history (BOH) & $2(3.22)$ & 0 \\
\hline Abnormal lie & $2(3.22)$ & $4(1.00)$ \\
\hline Failed induction & 0 & $4(1.00)$ \\
\hline Failed vacuum & 0 & $1(.25)$ \\
\hline Heart disease & $1(1.61)$ & $1(.25)$ \\
\hline Twin & 0 & $3(.75)$ \\
\hline Previous myomectomy & $1(1.61)$ & 0 \\
\hline Previous uterine rupture & $1(1.61)$ & 0 \\
\hline Sub fertility & 0 & $1(.25)$ \\
\hline
\end{tabular}


The mean blood loss in elective cs was $236.29 \pm 74.2 \mathrm{ml}$ and in emergency cs was $228.92 \pm 78.85 \mathrm{ml}$. The study showed higher blood loss in elective cases than in emergency ones; however this was not statistically significant (Table 4).

Table 4: Mean blood loss
\begin{tabular}{|l|c|c|c|}
\hline & \multicolumn{2}{|c|}{ Type of cesarean section } & P value \\
\cline { 2 - 3 } & Elective cs & Emergency cs & \\
\hline Mean blood loss & $236.29 \pm 74.2$ & $228.92 \pm 78.85$ & 0.442 \\
\hline
\end{tabular}

There were no maternal complications in elective cesarean group. However, there were 8 cases of maternal complications in emergency cs, the incidence being $2 \%$. The complications seen in emergency cs were $3(37.5 \%)$ cases of postpartum hemorrhage and $1(12.5 \%)$ case each of high spinal block, postpartum eclampsia, puerperal pyrexia, rectus sheath hematoma and wound infection. There were increased maternal complications in emergency group but it was not statistically significant (Table 5).

There were no cases of maternal mortality during the study period.

Table 5: Maternal complications
\begin{tabular}{|l|c|c|c|}
\hline \multirow{2}{*}{ Maternal complications } & Type of cesarean section & \multirow{2}{*}{ P value } \\
\cline { 2 - 3 } & $\begin{array}{l}\text { Elective } \\
\text { cs }(\mathbf{n}=\mathbf{0})\end{array}$ & $\begin{array}{c}\text { Emergency } \\
\text { cs(n=8,2\%) }\end{array}$ & \\
\hline Postpartum hemorrhage & 0 & 3 & \multirow{2}{*}{0.293} \\
\hline Puerperal pyrexia & 0 & 1 & \\
\hline Wound infection & 0 & 1 & \\
\hline Rectus sheath hematoma & 0 & 1 & \\
\hline Postpartum eclampsia & 0 & 1 & \\
\hline High spinal block & 0 & 1 & \\
\hline
\end{tabular}

There were 7 cases of poor Apgar score in emergency cs. There were no cases of poor Apgar score in elective group. However this difference was not statistically significant (Table 6).

Table 6: Apgar score
\begin{tabular}{|c|c|c|c|}
\hline Apgar score & \multicolumn{2}{|c|}{ Type of cesarean section } & P value \\
\cline { 2 - 3 } & Elective cs & Emergency cs & \\
\hline Poor & 0 & 7 & .0576 \\
\hline Good & 62 & 392 & \\
\hline
\end{tabular}

Regarding NICU admission, there were 12 cases of NICU admission in emergency cesarean section, the rate of admission being $3 \%$. No newborn were admitted in NICU in elective group. And this difference in the rate of admission was not statistically significant (Table 7).

\section{Table 7: NICU admission}

\begin{tabular}{|c|c|c|c|}
\hline \multirow{2}{*}{ NICU admission } & \multicolumn{2}{|c|}{ Type of cesarean section } & \multirow{2}{*}{ P value } \\
\cline { 2 - 3 } & Elective cs & Emergency cs & \\
\hline yes & 0 & 12 & \multirow{2}{*}{.166} \\
\hline no & 62 & 387 & \\
\hline
\end{tabular}

There was no case of perinatal mortality during the study period.

\section{DISCUSSION}

Cesarean section is the most commonly performed life saving procedure in obstetrics; however it is associated with increased maternal and fetal complications.

In our study, the rate of cesarean section was $36.76 \%$ of total deliveries. In the study conducted by Suwal $A^{8}$ in tertiary level centre in Kathmandu, the incidence of cs was $22.3 \%$. A retrospective study was conducted in Zambia by Sichundu et al in which cs rate was $26.72 \%$ and in a study at India by Daniel S et al, ${ }^{10}$ the rate of cs was $28.7 \%$. The average global rate of cs is $18.6 \%$. The higher rate of cs in our centre can be explained by the fact that it is the referral centre of Province no. 4 where we get a great ordeal of maternal and fetal complications, where usually the mode of delivery required is cesarean section.

The mean age in emergency group was less than in elective group in our study and this difference was statistically significant, and the result was similar to the studies done by Vesna Elvei-Gasparovic et al, ${ }^{11}$ Renuka $\mathrm{P}^{12}$ and Thakur V et al. ${ }^{13}$

Regarding booking status in our study, unbooked cases underwent emergency cs more than elective cs and this finding was statistically significant. The study by Diana $V^{20}$ also showed that women with no antenatal care were supposed to have more chance of emergency cs. With no proper supervision during pregnancy, women tend to seek advice only when complications arise. Hence we may conclude that regular antenatal visit may play a significant role in lowering the emergency cesarean rate.

The most common indication of cs in both groups was previous cs. The other indications for emergency cs were mainly fetal indications like oligohydraminos, meconium stained liquor, cephalopelvic disproportion and fetal heart rate abnormalities in our study. Various other studies support our findings. ${ }^{14-17}$ So, we should all focus on reducing the primary cesarean rate to decrease the overall cesarean rate globally by revising our indications and standardizing instrumental delivery, which has become obsolete these days.

Maternal complications were seen in $2 \%$ of emergency cs whereas no complication was seen in elective group. However this difference was not statistically significant. Burshan et $\mathrm{al}^{18}$ also stated that emergency cs was associated with increased maternal morbidities and it was statistically significant in their study. This statistical insignificance in our study may be due to less number of patients in elective group. The complications like PPH, puerperal pyrexia, high spinal block, rectus sheath hematoma and wound infection were seen in emergency cesarean group in our study. Various studies showed different complications. In the study done by Ghazi et $\mathrm{al}^{19}$ in Pakistan, maternal complications were higher in cs group, the most common being postoperative anaemia. In the study by Santhanalakshmi et $\mathrm{al}^{20}$, the most common maternal complications in emergency group were primary hemorrhage and bladder injury. This difference in the pattern of maternal complications in various studies may be due to difference in indications of cesarean section, level of care provided in different hospitals and designation of service provider. 
There were no cases of maternal mortality in either group in our study. This may be due to efficient management of cases in our center, as well as short study duration. In the study by Gurunule $A A^{16}$ the incidence of maternal mortality in emergency cs was $0.3 \%$ and no mortality in elective group. Various studies showed that maternal mortality was higher in emergency group than in elective group..$^{17,21,22}$ Such differences may be due to the fact that elective cases are performed on prearranged time with optimization of both maternal and fetal conditions whereas emergency ones are done due to unseen maternal and fetal risks, predisposing to increased risk of complications.

Regarding fetal outcome, emergency cesarean section was associated with poor Apgar score and increased NICU admission, as majority of emergency cs were done for fetal indications. However these findings were not significant statistically. In the study by Schindu $\mathrm{P}$ et al, ${ }^{9} 11.4 \%$ of emergency cs and $9.8 \%$ of cases in elective group had poor perinatal outcome but this finding was not significant. Similar results were depicted by other studies as well. ${ }^{11,17,23}$ There were no cases of perinatal mortality in our study.

\section{CONCLUSION}

The rate of cesarean section is high in a tertiary care centre. Emergency cesarean is always associated with increased maternal and perinatal complications than in elective cesarean ones.

\section{RECOMMENDATIONS}

Since we are aware of the fact that cesarean sections are always associated with increased maternal and perinatal

\section{REFERENCES}

1. Cunningham FG, Leveno KJ, Bloom SL, Spong CY, Dashe JS, Hoffman $\mathrm{BL}$, Casey BM SJ, editor. Cesarean delivery and peripartum hysterectomy. In: Williams Obstetrics. 24th ed. Mc Graw Hill Education; 2014. p. 587-609.

2. Liu S,Liston RM, Joseph KS, Heaman M, Sauve R, Krames MS. Maternal Mortality And Severe Morbidity Associated With Low Risk Planned Cesarean Delivery Versus Plannned Vaginal Delivery At Term. Can Med Assoc J. 2007;176(4):455-60.PMID:17296957

3. Jackson N, Paterson-Brown S. Physical Sequelae Of Caesarean Section. Best Pract Res Clin Obstet Gynaecol. 2001;15(1):49-61. PMID:11359314

4. Martin JA, Hamilton BE, Sutton PD, Ventura SJ, Menacker F, Mathews TJ. Births: Final Data for 2011. Natl Vital Stat Reports. 2013;62(1):1-69. PMID:24974591

5. World Health Organization.Appropriate Technology For Birth. Lancet. 1985:WHO Statement on Caesarean Section Rates. 1985;2(8452):436-437.PMID:2863457

6. Betran AP, JianFeng Y, Moller AB, Jun Z, Gulmezoglu AM, Torloni MR. The Increasing Trend In Caesarean Section Rates: Global, Regional And National Estimates: 1990-2014. PLoS ONE. 2016;11(2): e0148343.DOI:10.1371/journal.pone.0148343

7. Villar J, Valladares E, Wojdyla D, Zavaleta N, Carroli G, Velazco A, Shah A, Campodonico L, Bataglia V, Faundes A, Narvez A, Donner A, Romero M, Reynoso S, Simonia de Padua K, Giordano D, Kublickas M, Acosta A. Caesarean Delivery Rates And Pregnancy Outcomes : The 2005 WHO Global Survey On M aternal And Perinatal Health. 2005 WHO Global Survey Maternal Perinatal Health. 2006;1819-29. DOI:10.1016/50140-6736(06)68704-7 risks than vaginal delivery, this study recommends in reducing cesarean delivery in both the emergency or elective ones by revisiting our indications for cesarean sections, decreasing our fear of litigations, by standardizing the skills of instrumental delivery of the nursing staffs, doctors and also encouraging patients to have regular antenatal care so that any complications can be caught earlier and treated before it's too late.

\section{LIMITATION OF STUDY}

This study was done for a short duration of time. The sample size of study population was also small and there was significant difference in the number of patients in emergency and elective group. So the differences seen were not statistically significant in most of our findings. So the findings cannot be generalized.

\section{ACKNOWLEDGEMENT}

We would like to thank first the Institution Review Committee for granting us the permission to conduct the study. We would also like to express our gratitude to the hospital administration for allowing us to conduct the study in the department of Obstetrics and Gynecology of Manipal Teaching Hospital. We also like to acknowledge the help received from our students and residents.

\section{CONFLICT OF INTEREST}

We declare no conflict of interest.

\section{FINANCIALDISCLOSURE}

None

8. Suwal A,Shrivastava VR, Giri A. Maternal And Fetal Outcome In Elective And Emergency Cesarean Section. I Nepal Med Assoc. 2013;52(8):563-6. https://doi.org/10.31729/jnma.2426

9. Sichundu P, Siziya S, Kumoyo M. Rate , Indications And Fetal Outcome Of Emergency Caesarean Section-A Retrospective Study At Ndola Teaching Hospital, Ndola, Zambia. Asian Pacific Journal of Health Science. 2017;4(2):162-7. DOI:10.21276/apjhs.2017.4.2.27

10. Daniel S, Vishwanathan M, Simi BN, Nazeema A. Comparison of Fetal Outcomes of Emergency and Elective Caesarean Sections in a Teaching Hospital in Kerala. Acad Med J India. 2014;2(1):32-6.

11. Elvedi V, Klepac-pulani T, Peter B. Maternal and Fetal Outcome in Elective versus Emergency Caesarean Section in a Developing Country. Coll Antropol 30. 2006;30:113-8. PMID: 16617584

12. Renuka P, Suguna V. A Comparative Study of Maternal and Foetal Outcomes in Patients Undergoing Elective Or Emergency Cesarean Section. J Med Sci Clin Res. 2017;4(12):15059-69. DOI:10.18535 /jmscr/v4i12.123

13. Thakur V,Chiheriya H, Thakur A, Mourya S. Study Of Maternal And Fetal Outcome In Elective And Emergency Caesarean Section.International Journal of Medical Research and Review. 2015;3(11):1300-5. DOI:10.17511/ijmrr.2015.i11.236

14. Diana V, Tipandjan A. Emergency And Elective Caesarean Sections: Comparison Of Maternal And Fetal Outcomes In A Suburban Tertiary Care Hospital In Puducherry. Int J Reprod Contracept Obs Gynecol. 2016;5(9):3060-5.DOI: 10.18203/2320-1770-ijrcog20162985

15. Soren R, Maitra N, Patel PK, Sheth T. Elective Versus Emergency Caesarean Section: Maternal Complications and Neonatal Outcomes. IOSR J Nurs Heal Sci. 2016;5(5):2320-40. DOI:10.9790/ 19590505080104 
16. Gurunule AA, Warke HS. Maternal And Foetal Outcome In Elective Versus Emergency Caesarean Sections. Int J Reprod Contracept Obs Gynecol. 2017;6(4):1222-8. DOI:10.18203/2320-1770.ijrcog

17. Govind KI, TV R. Obstetric Outcome In Elective Vs Emergency Cesarean Section. Paripex Indian Journal of Research. 2018;3:7-8.

18. Burshan M N, Abusnena O, Alhamdi R M, Oommen S, ElHeggiagi MA. Emergency Caesarien Section Among Libyan Women At Khaddar Hospital,Tripoli, Libya. IOSR-JDMS. 2015;14(1):20-2.

19. Ghazi A, Karim F, Hussain AM, Ali T, Jabbar S. Maternal Morbidity In Emergency Versus Elective Caesarean Section At Tertiary Care Hospital. Journal of Ayub Medical College of Abbotabad. 2012;24(1):10-13.

20. Santhanalakshmi C, Gnanasekaran V . A Retrospective Analysis Of Caesarean Section In A Tertiary Care Hospital. IJSR. 2013;6(14): 2097-9.
21. Gandhi K, Dahiya K. Maternal And Neonatal Outcome In 1000 Caesarean Sections.International Journal of Health care and Biomedical Research. 2017;5(3):123-34.

22. Zahid N, Munawar I, Aslam A, Mirza SA. Comparison of Outcome in Patients Undergoing Elective and Emergency Caesarean Section.Journal of Rawalpindi Medical College. 2016;20(1):56-8.

23. Benzouina S, Boubkraoui MEM, Mrabet M, Chahid N, Kharbach A, ElHassani A,Barkat Al. Fetal Outcome In Emergency Versus Elective Cesarean Sections At Souissi Maternity Hospital, Rabat, Morocco.The Pan African medical journal. 2016;23:197. DOI:10.11604/pamj. 2016.23.197.7401 